Article

\title{
Effect of ECAP Deformation Route on the Degree of Anisotropy of Microstructure of Extremely Low CN Fe-20mass\%Cr Alloy
}

\author{
Muhammad Rifai ${ }^{1}$, Hiroyuki Miyamoto ${ }^{2, *}$ and Hiroshi Fujiwara ${ }^{2}$
}

1 Graduate School of Science and Engineering, Doshisha University, 1-3 Tatara Miyakodani, Kyotanabe, Kyoto 610-0394, Japan; E-Mail: eum1504@mail4.doshisha.ac.jp

2 Department of Mechanical Engineering, Doshisha University, 1-3 Tatara Miyakodani, Kyotanabe, Kyoto 610-0394, Japan; E-Mail: hifujiwa@mail.doshisha.ac.jp

* Author to whom correspondence should be addressed; E-Mail: hmiyamot@mail.doshisha.ac.jp; Tel./Fax: +81-774-65-6406.

Received: 20 December 2013; in revised form: 13 February 2014 / Accepted: 20 February 2014 / Published: 27 February 2014

\begin{abstract}
The effect of the deformation route on the microstructural evolution of low $\mathrm{CN}$ $\mathrm{Fe}-20 \% \mathrm{Cr}$ alloy by ECAP has been investigated, with a focus on the anisotropy of the microstructure. This alloy was pressed at $423 \mathrm{~K}$ from one, two and four passes via routes $\mathrm{A}, \mathrm{Bc}$ and $\mathrm{C}$, and the microstructure was observed three dimensionally. As has been acknowledged, overall grain fragmentation proceeded most effectively in route $\mathrm{Bc}$, and the highest hardness was obtained following routes $\mathrm{C}$ and A. However, the degree of anisotropy of microstructural development is different among the three deformation routes. The fractions of the high angle grain boundary (HAGB) and mean grain boundary misorientation were high and nearly isotropic in route $\mathrm{Bc}$, whereas they are considerably low in one direction and highly anisotropic in routes A and C. Most importantly, those two parameters and hardness are the highest in route $\mathrm{C}$ if limited to the transverse direction, i.e., normal to both the insert and extruding directions. This result contrasts with FCC materials which most papers report as having the highest fraction of HAGB in route Bc. This result can be interpreted by the slip irreversibility of screw dislocations which is predominant in BCC metals.
\end{abstract}

Keywords: EBSD; steel; equal-channel angular processing; grain boundaries; anisotropy 


\section{Introduction}

Application of severe plastic deformation (SPD) as a process of fabricating ultrafine grained (UFG) material to the sub micrometer level increased in popularity for 25 years in the field of materials science and engineering [1]. This popularity is partially explained by the new techniques of SPD that have been developed to introduce ultrafine grain microstructures in polycrystalline materials. Equal Channel Angular Pressing (ECAP) is a type of SPD used to produce UFG material. ECAP is unique because the deformation proceeds by incremental shear restricted to the narrow zone parallel to the intersecting plane of the two channels [2,3]. The majority of papers on SPD materials have been devoted to the face-centered cubic (FCC) materials such as Al [4], $\mathrm{Cu}$ [5] and Ni [6]. Body-centered cubic (BCC) metals such as tungsten [7,8], and carbon steels [9] have mostly been studied from a practical viewpoint.

Several reports on the influence of ECAP parameters on microstructural evolution and mechanical properties, such as die angle, pressing speed, temperature die and deformation route have been published. Langdon found that a $90^{\circ}$ inner angle was most efficient for grain refinement [10]. Many concepts have been recommended for explaining the effect of deformation route on microstructure and mechanical properties, especially in FCC material. Other studies have found that route $\mathrm{Bc}$ is the most efficient for producing isotropy microstructure and HAGB [11-13] due to the $90^{\circ}$ crossing shear planes in every pass and the simple equiaxed grain structure. There are four basic techniques of ECAP: in route $\mathrm{A}$, the specimen is processed without any rotation; in route $\mathrm{B}_{\mathrm{A}}$, the specimen is rotated by $90^{\circ}$ in an alternate direction between consecutive passes; in route $\mathrm{B}_{\mathrm{C}}$, the specimen is rotated $90^{\circ}$ counterclockwise between each pass; while in route $\mathrm{C}$ the specimen is rotated by $180^{\circ}$ between passes [13]. There are many reports concerning the effective deformation route for grain refinement in FCC metals, but there are limited studies on BCC. When the UFG materials are applied to structural materials, the anisotropy of microstructure is crucially important because surface phenomena such as corrosion, oxidation and corrosion fatigue depend on the surface microstructure. In order to improve resistance to such degradations, it is important to characterize and control the anisotropy of the microstructure as well as average bulk microstructure. However, the degree of anisotropy on microstructural development has not been carefully evaluated so far, especially in BCC metals $[10,11,15,16]$. Effects of the pass number and deformation route on the microstructure, mechanical and electrochemical properties considering the degree of anisotropy will be discussed in detail in this report.

\section{Experimental Section}

The material used in this experiment has a chemical composition of low $\mathrm{CN} \mathrm{Fe}-20 \% \mathrm{Cr}$ alloy with Cr 20.03; C 0.0004; N 0.0013 and Fe balance (in mass percent). This material is machined with dimensions of $7.95 \mathrm{~mm} \times 7.95 \mathrm{~mm} \times 100 \mathrm{~mm}$ for ECAP pressing. ECAP procedures are carried out using a split die with two channels intersecting at an inner angle of $90^{\circ}$ and an outer angle of $0^{\circ}$. The ECAP system can be seen in Figure 1a,b. ECAP was carried out at $423 \mathrm{~K}$. The samples were lubricated with high temperature fluorine lubricating grease and pressed from one, two and four passes via routes $\mathrm{A}, \mathrm{Bc}$ and $\mathrm{C}$. The deformation stages of route $\mathrm{A}, \mathrm{Bc}$ and $\mathrm{C}$ are simulated in Figure 1c Microstructure 
quantification using orientation map observation and mechanical properties were analyzed during grain refinement process using SPD. A scanning electron microscope of the field-emission type (FE-SEM, JSM 7001F), equipped with electron back-scattered diffraction (EBSD, Oxford Instrument Co., Osfordshire, UK) image, and a transmission electron microscope (TEM) were used to examine the microstructures. EBSD orientation maps were processed using INCA ${ }^{\mathrm{TM}}$ software (Oxford Instruments, Osfordshire, UK). The micro hardness experiments were performed on a Vickers hardness testing machine at room temperature.

Figure 1. (a) Equal Channel Angular Pressing (ECAP) system; (b) Schema ECAP of route $\mathrm{A}, \mathrm{Bc}$, and $\mathrm{C}$; (c) ECAP equipment.

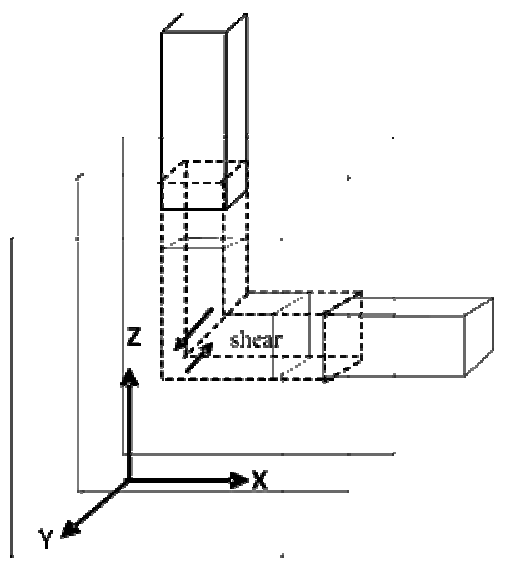

(a)

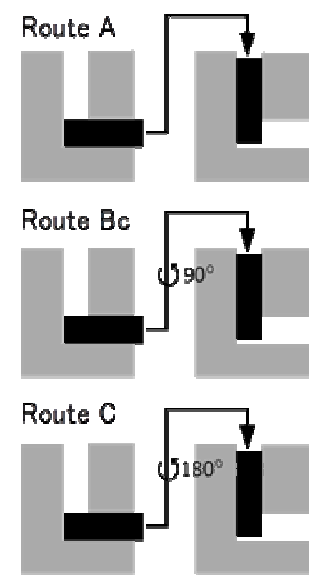

(b)

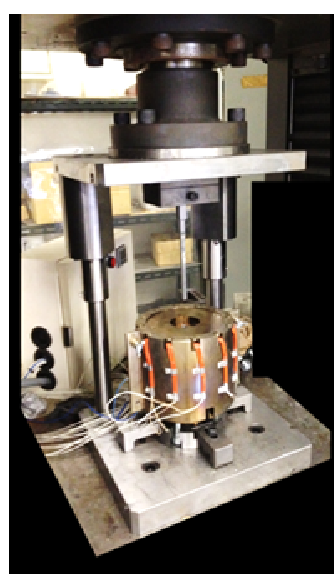

(c)

\section{Experimental Results}

Microstructural observation and texture analysis revealed that the process of grain refinement by severe plastic deformation can be divided into different stages as is shown in Figure 2 for several kinds of deformation route. Figure 2 was obtained by EBSD on X, Y and Z planes by ECAP for one, two and four passes. Due to the low orientation resolution, boundaries with misorientation smaller than $2^{\circ}$ were omitted. It is apparent that grains are finely subdivided after one pass of ECAP. After two passes, arrays of planar and extended grain boundaries are developed parallel to the macroscopic ECAP shear plane in all the deformation routes.

After four passes via route A, grain boundaries, mostly HAGB, are set in the planar parallel boundaries whereas via route $\mathrm{Bc}$, microstructures are more isotropic and equiaxed grain substructure can be recognized. In route $\mathrm{C}$, the density of HAGB is anisotropic, and it is highest in the Y-plane as are those in route $\mathrm{A}$, but they are still observed in the $\mathrm{X}$ and $\mathrm{Z}$ planes. It seems that HAGB are a collection of planes with an axis parallel to the $Y$-axis in common in route $\mathrm{C}$.

Quantitative analysis of microstructures by EBSD is shown in Figure 3. The fraction of HAGB and average misorientation increased with increasing equivalent strain. These data also confirmed that route $\mathrm{Bc}$ is more isotropic than routes $\mathrm{A}$ and $\mathrm{C}$ at four passes. Note that HAGB and average misorientation are extremely low in the Z-plane in routes A and $\mathrm{C}$, reflecting the anisotropic array of the boundaries as is shown in Figure 2. It is also important to note that both the fraction of HAGB and average misorientation is highest in route $\mathrm{C}$ if they are limited to the Y-plane. It indicated that the 
grains are extended in the $Y$-direction and the deformation-induced boundaries are collections of grain boundaries nearly parallel to the $Y$-axis in common.

Figure 2. 3D Misorientation map of low CN Fe-20\%Cr alloy after ECAP (a) one pass; (b) two passes route $\mathrm{A}$; (c) two passes route $\mathrm{Bc}$; (d) two passes route $\mathrm{C}$; (e) four passes route $\mathrm{A} ;(\mathbf{f})$ four passes route $\mathrm{Bc} ;(\mathbf{g})$ four passes route $\mathrm{C}$.

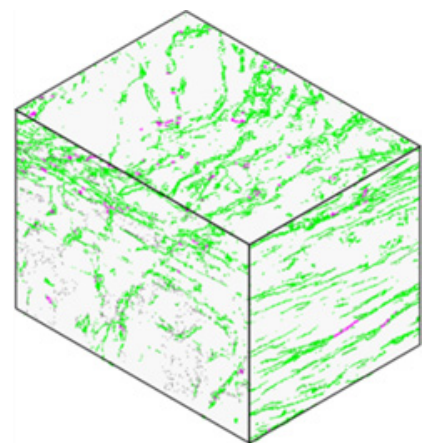

(a)

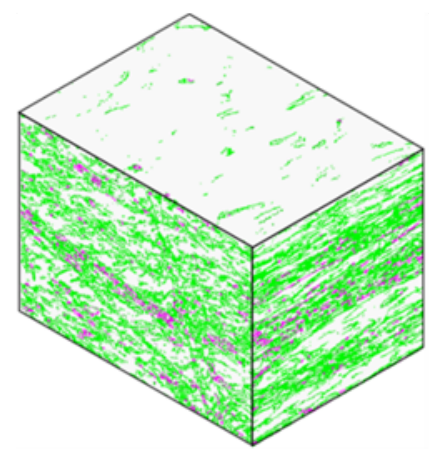

(b)

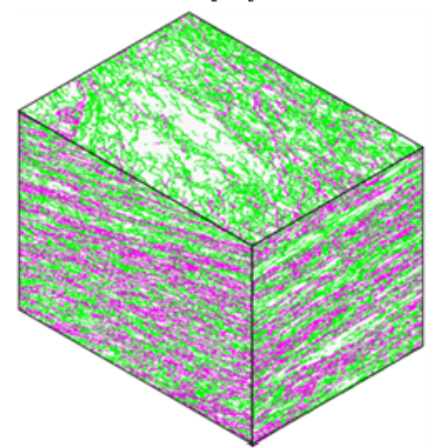

(e)

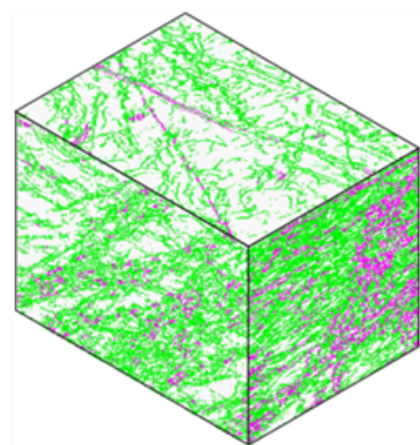

(c)

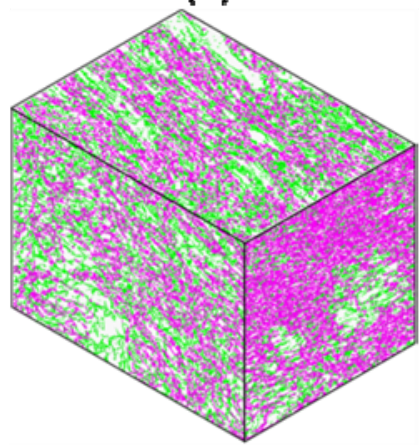

(f)

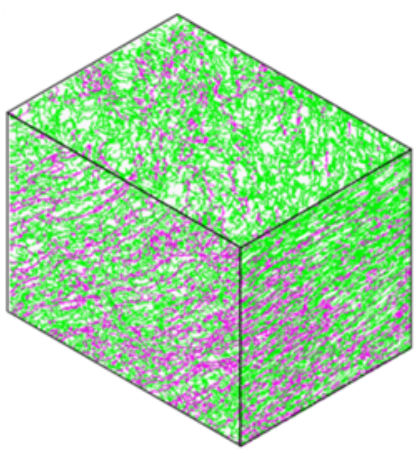

(d)

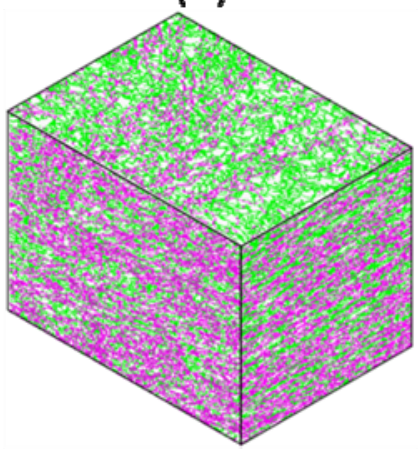

(g)<smiles>[Y]C([Z])[Y]</smiles> 
Figure 3. High angle grain boundary fraction of ECAP processed with respect to three orthogonal planes for $(\mathbf{a})$ route $\mathrm{A}$; $(\mathbf{b})$ route $\mathrm{Bc}$ and $(\mathbf{c})$ route $\mathrm{C}$; and mean misorientation angle for $(\mathbf{d})$ route $\mathrm{A} ;(\mathbf{e})$ route $\mathrm{Bc}$ and $(\mathbf{f})$ route $\mathrm{C}$.

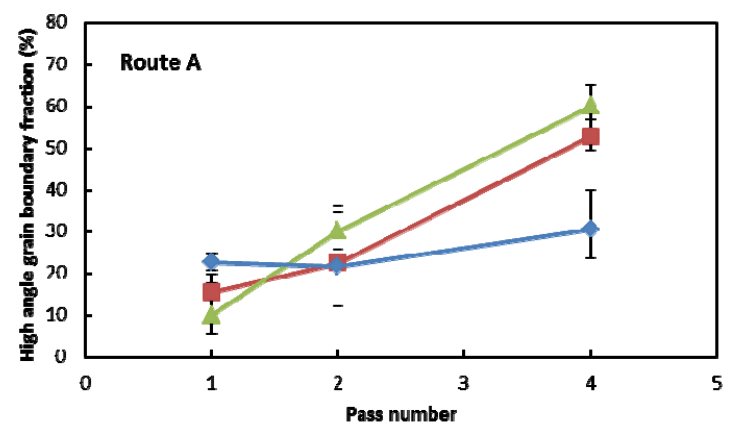

(a)

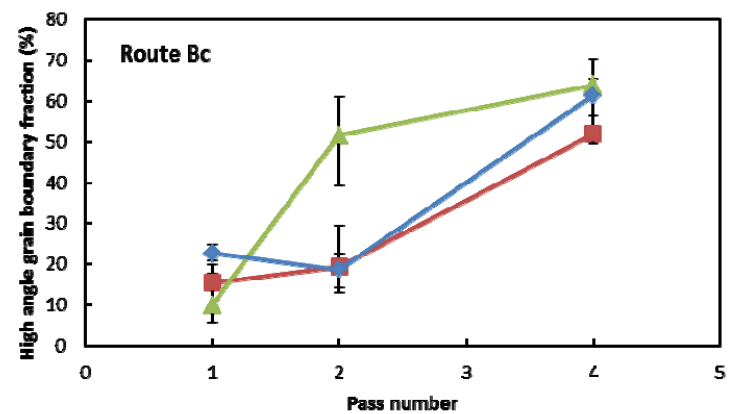

(b)

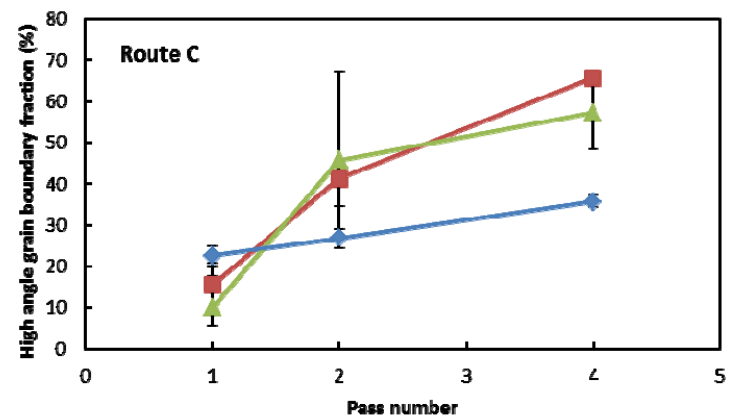

(c)

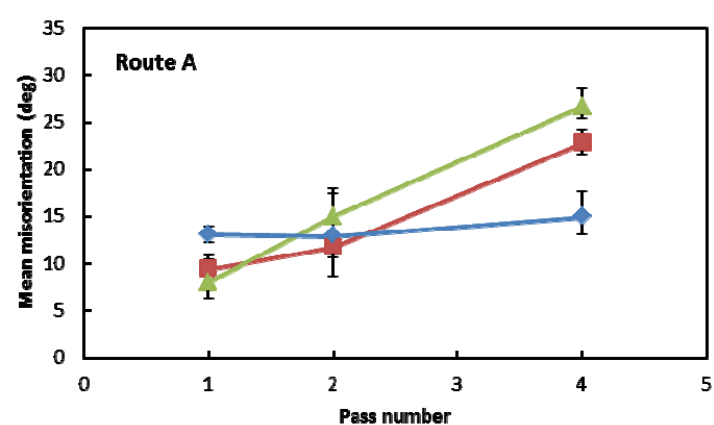

(d)

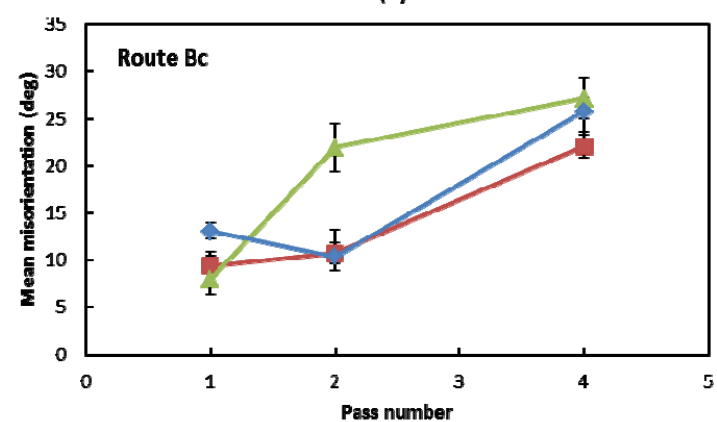

(e)

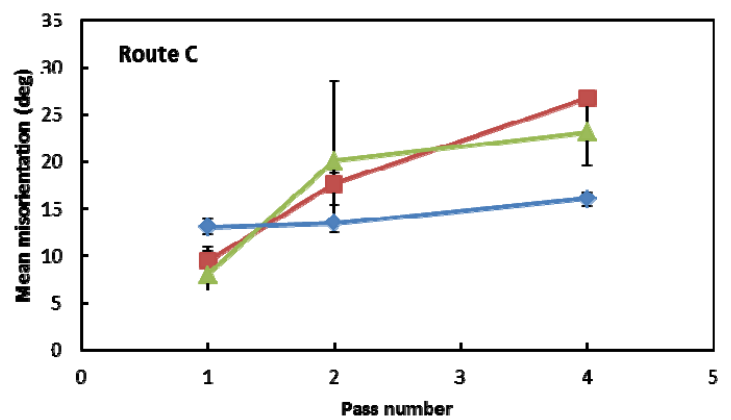

(f)

Figure 4 shows the texture after four passes in three orthogonal planes. The degree of development of textures or orientation scattering is different on the three orthogonal planes in routes $\mathrm{A}, \mathrm{Bc}$ and $\mathrm{C}$. The degree of scattering is the lowest in route $\mathrm{A}$, whereas it is the highest and isotropic in route $\mathrm{Bc}$ overall in the three planes. In contrast, in route $\mathrm{C}$, it is very anisotropic, and very scattered in $\mathrm{Y}$-plane. If it is limited to the $\mathrm{Y}$-plane, the degree of scattering is the highest in route $\mathrm{C}$ among the three routes. The texture in the $\mathrm{Y}$ plane in route $\mathrm{C}$ appears a collection of orientation rotated around the $Y$-axis. In Figures 2 and 4, the HAGBs in route $\mathrm{C}$ are the collections of the tilt boundaries having a misorientation axis parallel to the $Y$-axis. 
Figure 4. $\{100\}$-Pole figure of low CN Fe-20\%Cr alloy after four passes of ECAP.

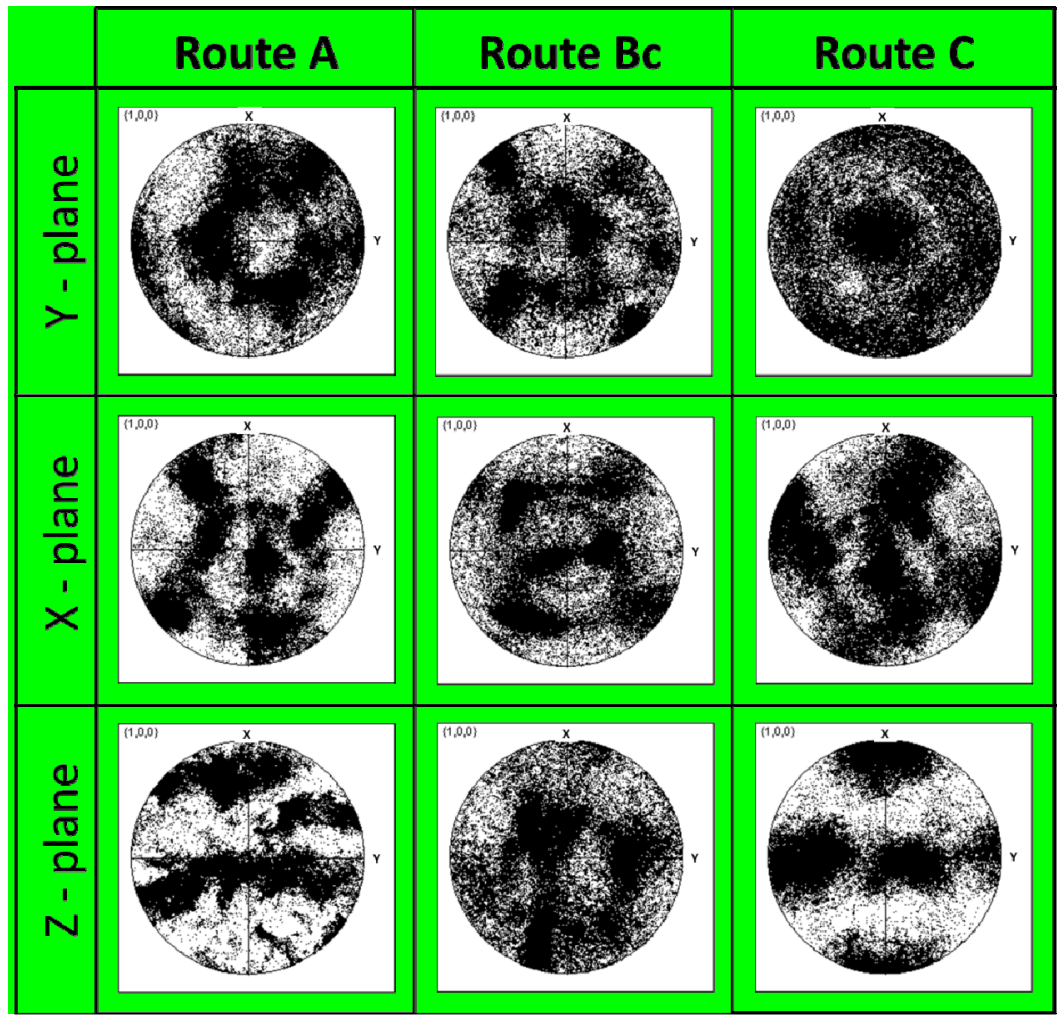

Micro hardness measured on $\mathrm{X}, \mathrm{Y}$ and $\mathrm{Z}$ planes after ECAP is shown in Figure 5. The hardness after a single pass increased significantly, and increased with an increasing number of passes. The micro hardness via route $\mathrm{Bc}$ is isotropic with small differences compared to routes $\mathrm{A}$ and $\mathrm{C}$. In routes $\mathrm{A}$ and $\mathrm{C}$, the hardness on the Z-plane is very low, and reflects the low HAGB.

Figure 5. Microhardness after ECAP for low $\mathrm{CN}$ Fe-20\%Cr alloy with (a) route A, (b) route $\mathrm{Bc}$ and $(\mathbf{c})$ route $\mathrm{C}$.

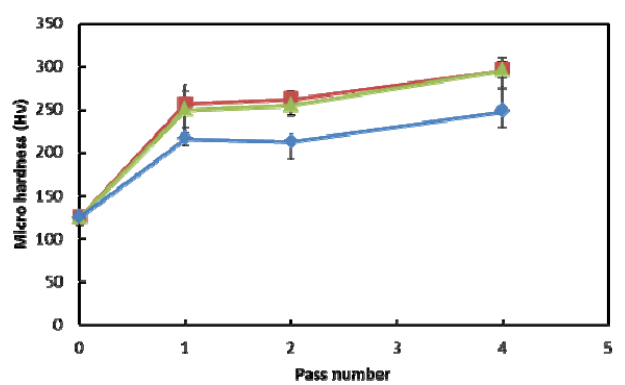

(a)

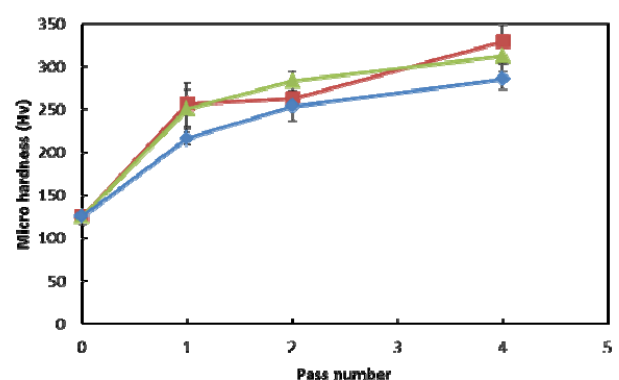

(b)

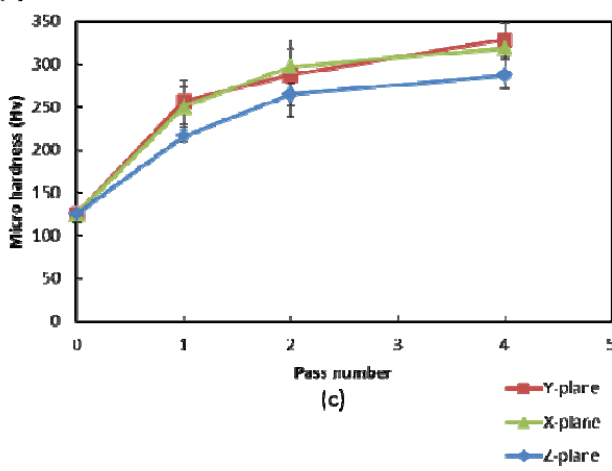




\section{Discussion}

The present materials with extremely low $\mathrm{C}$ and $\mathrm{N}$ are interstitial-free steel, and the effect of solute atoms on the development of microstructure can be neglected. Therefore, one can examine the microstructural evolution in terms of crystal slip intrinsic to BCC structures. Since the Peierls potential of screw dislocations is higher than that of edge dislocation in BCC crystals, slip by screw character is more predominant than by edge dislocation. When plastic straining increases by the formation and extension of dislocation loops, edge dislocations characters with high mobility slip faster than screw dislocations character with lower mobility, resulting in extended lines of screw dislocations. These extended dislocation loops in BCC metals were indeed observed by TEM frequently. Therefore, nature of the slip intrinsic to screw dislocation has influence on the macroscopic behavior of plastic deformation. Well-known deformation behaviors peculiar to BCC are the dominant cross-slip by screw character, dynamic recovery and tension/compression asymmetry attributed to slip irreversibility of screw character, etc.

In ECAP, deformation-induced boundaries develop parallel to the most shear-stressed slip plane parallel to the macroscopic shear plane of ECAP. Therefore, the grain boundaries tend to develop as a set of parallel boundaries nearly parallel to the shear plane in routes $\mathrm{A}$ and $\mathrm{C}$ where the shear planes are nearly parallel in successive passes. On the other hand, the shear planes in the successive passes rotate with a wide range of angle viewed from all the orthogonal planes in route Bc. Thus, grains tend to be equiaxial and isotropic in route $\mathrm{Bc}$. However, there is a difference in the alignment and fraction of $\mathrm{HAGB}$ between routes $\mathrm{A}$ and $\mathrm{Bc}$.

In route $\mathrm{A}$, the shear plane and shear direction in the successive passes are almost constant, and the same slip system is activated in successive passes. Thus, the orientation is stable, leading to defined texture. Since the deformation-induced boundary forms parallel to the most activated slip plane close to the shear plane, a single set of parallel HAGB is formed in route A.

In route $C$, the shear is reversed in alternative passes in the same shear plane. Since the slip reversibility is low in BCC compared to that in FCC because of the dominant screw dislocation, a different slip system can be activated in the forward and reverse shear deformations. Therefore, stable end orientation in the two opposite shears is different, leading to orientation scattering around the $Y$-axis.

\section{Conclusions}

The microstructural evolution of extremely low $\mathrm{CN}$ Fe-20mass\% $\mathrm{Cr}$ alloy processed by ECAP for up to four passes via routes $\mathrm{A}, \mathrm{Bc}$ and $\mathrm{C}$ was quantitatively analyzed by EBSD focusing on the degree of anisotropy. The degree of anisotropy of microstructures and the array of deformation induced HAGB were different among the three deformation routes. They are generally isotropic in route Bc, namely, grains were equiaxial, and the density and fraction of HAGB are comparable in the three orthogonal planes. On the other hand, they are more anisotropic in routes A and $\mathrm{C}$. The fraction of HAGB, mean misorientation and hardness are highest in route $\mathrm{C}$ if compared by the Y-plane only. The grains are extended into the $Y$-axis, and HAGB are collections of boundaries parallel to the $Y$-axis in 
common in route $\mathrm{C}$. These results contrast with $\mathrm{FCC}$, and can be interpreted in terms of slip irreversibility peculiar to BCC crystals.

\section{Acknowledgments}

The authors gratefully acknowledge the financial support of a Grant-in-Aid for Scientific Research on Innovative Areas “Bulk nano metals," MEXT Japan (No 25102710).

\section{Conflicts of Interest}

The authors declare no conflict of interest.

\section{References}

1. Langdon, T.G. Twenty-five years of ultrafine-grained materials: Achieving exceptional properties through grain refinement. Acta Mater. 2013, 61, 7035-7059.

2. Valiev, R.Z.; Islamgaliev, R.K.; Alexandrov, I.V. Bulk nanostructured materials from severe plastic deformation. Prog. Mater. Sci. 2000, 45, 103-189.

3. Valiev, R.Z.; Langdon, T.G. Principles of equal-channel angular pressing as a processing tool for grain refinement. Prog. Mater. Sci. 2006, 51, 881-981.

4. Tolaminejad, B.; Brisset, F.; Baudin, T. EBSD study of the microstructure evolution in a commercially pure aluminium severely deformed by ECAP. Mater. Sci. Eng. 2012, 32, 012025.

5. Orlov, D.; Vinogradov, A. The control of texture to improve high-cyclic fatigue performance in copper after equal channel angular pressing. Mater. Sci. Eng. A 2011, 530, 174-182.

6. Neishi, K.; Horita, Z.; Langdon, T.G. Grain refinement of pure nickel using equal-channel angular pressing. Mater. Sci. Eng. A 2002, 325, 54-58.

7. Hao, T.; Fan, Z.Q.; Zhao, S.X.; Luo, G.N.; Liu, C.S.; Fang, Q.F. Microstructures and properties of ultrafine-grained tungsten produced by equal-channel angular pressing at low temperatures. J. Nuclear Mater. 2013, 433, 351-356.

8. Zhang, Y.; Ganeev, A.V.; Wang, J.T.; Liu, J.Q.; Alexandrov, I.V. Observations on the ductile-to-brittle transition in ultrafine-grained tungsten of commercial purity. Mater. Sci. Eng. A 2009, 503, 37-40.

9. Shin, D.H.; Park, K.T. Ultrafine grained steels processed by equal channel angular pressing. Mater. Sci. Eng. A 2005, 410-411, 299-302.

10. Iwahashi, Y.; Horita, Z.; Nemoto, M.; Langdon, T.G. The process of grain refinement in equal-channel angular pressing. Acta Mater. 1998, 46, 3317.

11. Iwahashi, Y.; Furakawa, M.; Horita, Z.; Nemoto, M.; Langdon, T.G. Microstructural characteristic of ultrafine-grained aluminum produced using equal-channel angular pressing. Metal. Mater. Trans. A 1998, 29, 2245-2252.

12. Furukawa, M.; Horita, Z.; Nemoto, M.; Valiev, R.Z.; Langdon, T.G. Microhardness measurements and the Hall-Petch relationship in an Al-3\% Mg alloy with submicrometer grain size. Acta Mater. 1996, 44, 4619-4629. 
13. Furukawa, M.; Horita, Z.; Langdon, T.G. Factors influencing the shearing patterns in equal-channel angular pressing. Mater. Sci. Eng. A 2002, 332, 97.

14. Furukawa, M.; Iwahashi, Y.; Nemoto, M.; Langdon, T.G. The shearing characteristics associated with equal-channel angular pressing. Mater. Sci. Eng. A 1998, 257, 328-332.

15. Langdon, T.G. The principles of grain refinement in equal-channel angular pressing. Mater. Sci. Eng. A 2007, 462, 3-11.

16. Li, S.; Gazder, A.; Beyerlein, I.J.; Davis, H.J.C.; Pereloma, E.V. Microstructure and texture evolution during equal channel angular extrusion of interstitial-free steel: Effects of die angle and processing route. Acta Mater. 2007, 55, 1017-1032.

(C) 2014 by the authors; licensee MDPI, Basel, Switzerland. This article is an open access article distributed under the terms and conditions of the Creative Commons Attribution license (http://creativecommons.org/licenses/by/3.0/). 